\title{
Interaction of primary mast cells with Borrelia burgdorferi (sensu stricto): role in transmission and dissemination in C57BL/6 mice
}

Quentin Bernard ${ }^{1,4}$, Zhenping Wang ${ }^{2}$, Anna Di Nardo ${ }^{2}$ and Nathalie Boulanger ${ }^{1,3^{*}}$

\begin{abstract}
Background: Borrelia burgdorferi (sensu lato), the causative agent of Lyme borreliosis is a bacterium transmitted by hard ticks, Ixodes spp. Bacteria are injected into the host skin during the tick blood meal with tick saliva. There, Borrelia and saliva interact together with skin cells such as keratinocytes, fibroblasts, mast cells and other specific immune cells before disseminating to target organs.

Methods: To study the role of mast cells in the transmission of Lyme borreliosis, we isolated mouse primary mast cells from bone marrow and incubated them in the presence of Borrelia burgdorferi (sensu stricto) and tick salivary gland extract. We further analyzed their potential role in vivo, in a mouse model of deficient in mast cells (Kit ${ }^{\text {vsh }-/-}$ mice).

Results: To our knowledge, we report here for the first time the bacteria ability to induce the inflammatory response of mouse primary mast cells. We show that OspC, a major surface lipoprotein involved in the early transmission of Borrelia, induces the degranulation of primary mast cells but has a limited effect on the overall inflammatory response of these cells. In contrast, whole bacteria have an opposite effect. We also show that mast cell activation is significantly inhibited by tick salivary gland extract. Finally, we demonstrate that mast cells are likely not the only host cells involved in the early transmission and dissemination of Borrelia since the use of mast cell deficient Kit ${ }^{\text {wsh-/- }}$ mice shows a limited impact on these two processes in the context of this mouse genetic background.

Conclusions: The absence of mast cells did not change the replication rate of Borrelia in the skin. However, in the absence of mast cells, Borrelia dissemination to the joints was faster. Mast cells do not control skin bacterial proliferation during primary infection and the establishment of the primary infection, as shown in the C57BL/6 mouse model studied. Nevertheless, the Borrelia induced cytotokine modulation on mast cells might be involved in long term and/or repeated infections and protect from Lyme borreliosis due to the development of a hypersensitivity to tick saliva.
\end{abstract}

Keywords: Mast cells, Borrelia, Ixodes tick, Pathogen transmission, Kit ${ }^{\text {whh-/-}}$ mouse, Tick saliva

\footnotetext{
* Correspondence: nboulanger@unistra.fr

'EA7290 Virulence bactérienne précoce: groupe borréliose de Lyme,

Fédération de médecine translationnelle et Faculté de Pharmacie de

Strasbourg, Université de Strasbourg, Strasbourg, France

${ }^{3}$ Centre National de Reference Borrelia, Centre Hospitalier Universitaire,

Strasbourg, France

Full list of author information is available at the end of the article
} 


\section{Background}

Ixodes ticks are vectors of several pathogens including viruses (e.g. tick-borne encephalitatis virus), parasites (e.g. Babesia) and bacteria (e.g. Borrelia) [1]. They are transmitted to the host during the tick blood meal which lasts several days. Pathogens are inoculated into the skin with tick saliva. In the case of Lyme borreliosis, caused by B. burgdorferi (sensu lato) [2], bacteria first multiply in the skin before disseminating to target organs (heart, distant skin, joints) [3]. However, part of them persist for several weeks in the skin after transmission [4]. Skin cells, including keratinocytes, fibroblasts, endothelial cells, dendritic/Langerhans cells, $\mathrm{T}$ cells and mast cells (MCs), are those of immune importance since they are likely to be the first cells encountered by the bacteria [5]. Most of these cell functions have been shown to be inhibited by tick saliva compounds such as sialostatin $\mathrm{L}$ and Salp15 during bacteria transmission by $I$. scapularis ticks [6-12]. Notably, Salp15 protects B. burgdorferi (s.l.) from the host immune system by binding to the bacteria surface lipoprotein OspC [13]. OspC is a major Borrelia surface lipoprotein upregulated during the early transmission from the tick to the vertebrate host [14]. Moreover, Salp15 targets immune cells such as dendritic cells and $\mathrm{T}$ cells by inhibiting cytokine expression and cell maturation $[15,16]$. The tick saliva also inhibits other mechanisms such as hemostasis, pain and itch to increase tick blood meal efficiency [17]. Pathogens have evolved to use these saliva-associated inhibition mechanisms to increase their transmission rate [11].

MCs are widely distributed throughout the body with specific locations at the surface epithelia such as the skin, the lung and gastrointestinal and genitourinary tracts [18]. These cells are well known for their association with pathological conditions such as asthma, allergy or anaphylaxis. MCs are increasingly studied with new evidence of their involvement in parasitic, bacterial and viral infections. They can directly sense PathogenAssociated Molecular Patterns (PAMPs) through Pattern Recognition Receptors (PRRs) such as Toll Like Receptors (TLRs) [19]. They also can detect antigens through the binding of antibodies to their Fc receptors. MC response to pathogens depends on the PAMPs: some PAMPs induce only cytokine expression (TNF- $\alpha$, IL-6, IL-13, IL-1 $\beta$, IL-4, IL-5, IFN- $\gamma$ ) while others induce cytokine production as well as degranulation, a mechanism inducing preformed inflammatory mediator release [20]. In case of bacterial pathogenesis, the release of TNF- $\alpha$, histamine or vascular endothelial growth factor (VEGF) by MCs increase vascular permeability. Chemokines produced by MCs increase the inflammatory cell attraction at the infection sites (eosinophils, neutrophils, NK cells) [21]. MCs can also directly kill pathogens through antimicrobial peptides such as cathelicidins [22]. Moreover, their ability to present antigen and to secrete inflammatory mediators allows the recruitment of dendritic cells as well as T cells at the infection site. All these processes give them a central role between innate and adaptive immunity [23, 24].

MCs have been poorly studied in the context of Lyme borreliosis. Currently, it is known that murine MC lines respond to Borrelia by secreting TNF- $\alpha$ and by slowly degranulating. This activity seems to depend in part on surface proteins but not on the lipoprotein OspA [25]. Fc receptors seem to be involved through an antibodyindependent mechanism [26]. However, MC lines are not fully mature cells compared to bone marrow derived primary mast cells. In this study, for the first time we analyzed primary MCs response to B. burgdorferi (sensu stricto) and its lipoprotein OspC, a lipoprotein essential for the early bacterial transmission from the tick to the vertebrate host $[27,28]$. We also explored in vitro the tick saliva impact on MCs response to Borrelia. Finally, we used a murine $\mathrm{MC}$ deficient model to study their involvement in the in vivo infection process.

\section{Methods \\ Borrelia}

Borrelia burgdorferi (s.s.) strain 297 was cultured in BSK-H medium (Sigma-Aldrich, St. Quentin Fallavier, France) at $33{ }^{\circ} \mathrm{C}$, used at passage 8 in the late-log-phase, centrifuged, and then washed twice (30 min, 5000 $\times g$ ) with cell culture media. Borrelia burgdorferi (s.s.) 297, OspC-deficient and complemented mutants, have been described previously [14].

\section{Mast cell culture}

Primary MCs were generated by extracting bone marrow cells from the femurs of 4 to 8 week-old C57BL/6 mice and culturing the cells at $37{ }^{\circ} \mathrm{C}, 5 \% \mathrm{CO}_{2}$ in RPMI 1640 (Life Technologies, Villebon sur Yvette, France) supplemented with $10 \%$ inactivated FBS (Life Technologies), glutamine, non-essential amino acid (NEAA), penicillin/ streptomycin, and 2-mercaptoethanol. Recombinant murine IL-3 (1 ng/ml; R\&D Systems, Lille, France) and recombinant murine stem cell factor (SCF) (20 ng/ml; R\&D Systems) were used in vitro for differentiation of the MC precursor [29]. Medium was changed twice a week. After 4 weeks, MC maturation and purity were confirmed by the expression of CD117 and FceRI measured by flow cytometry and by metachromatic staining with toluidine blue. The purity of MCs was greater than $85 \%$ (Additional file 1: Figure S1).

\section{Mast cell degranulation and activation}

Degranulation was assessed by measuring the activity of $\beta$-hexosaminidase [30-32] in the supernatants of $1 \times 10^{5}$ MCs in $200 \mu \mathrm{l}$ Tyrode's buffer $(0.1 \%$ bovine serum 
albumin, $0.1 \%$ glucose, $2 \mathrm{mmol} / \mathrm{l} \mathrm{MgCl}_{2}, 137.5 \mathrm{mmol} / \mathrm{l}$ $\mathrm{NaCl}, 12 \mathrm{mmol} / \mathrm{L} \mathrm{NaHCO}_{3}, 2.6 \mathrm{mmol} / \mathrm{l} \mathrm{KCl}, \mathrm{pH}$ 7.4) incubated for $2 \mathrm{~h}$ at $37^{\circ} \mathrm{C}$ with different concentrations of B. burgdorferi (s.s.) (MOI 50:1 or 100:1), L-OspC (10 or $50 \mathrm{ng} / \mathrm{ml}$ ), unlipidated-OspC (10 or $50 \mathrm{ng} / \mathrm{ml}$ ) and/or saliva $(20 \mu \mathrm{g} / \mathrm{ml})$. For each sample assayed, supernatant aliquots $(20 \mu \mathrm{l})$ were mixed with substrate solution $(100 \mu \mathrm{l})$, which consisted of $1 \mathrm{mM} 4$-methylumbelliferyl2 -acetamide-2-deoxy- $\beta$-D-glucopyranoside (Calbiochem, Fontenay sous Bois, France) in 0.1 M sodium citrate buffer ( $\mathrm{pH} 4.5)$, and were incubated for $2 \mathrm{~h}$ at $37{ }^{\circ} \mathrm{C}$. The reaction was then stopped by the addition of $12 \mu \mathrm{l}$ of $0.2 \mathrm{M}$ glycine $(\mathrm{pH} 10.7)$. The reaction mixtures were excited at $365 \mathrm{~nm}$ and measured at $460 \mathrm{~nm}$ in a fluorescence plate reader (Gemini EM microplate spectrofluorometer, Molecular Devices). To determine the total cellular content of this enzyme, an equivalent number of cells were lysed with 1\% triton X-100 (Sigma-Aldrich) and the plate blank was deducted. Release of $\beta$ hexosaminidase was calculated as the percentage of the total enzyme content.

Inflammatory response was assessed by incubating $\mathrm{MCs}$ with different concentrations of B. burgdorferi (s.s.) (MOI $50: 1$ or $100: 1)$, L-OspC (10 or $50 \mathrm{ng} / \mathrm{ml}$ ), unlipidatedOspC (10 or $50 \mathrm{ng} / \mathrm{ml})$ and/or SGE $(20 \mu \mathrm{g} / \mathrm{ml})$ for 6 or $24 \mathrm{~h}$ at $37^{\circ} \mathrm{C}$. Cells and supernatants were collected and separated by centrifugation (300 g, $10 \mathrm{~min}$ ).

\section{Tick salivary glands}

SGE was obtained after dissection of female ticks fed for three days, and used at $20 \mu \mathrm{g} / \mathrm{ml}$ as described previously [7]. SGE was tested by the Limulus assay to check for the presence of endotoxins and was found to contain $<0.3$ endotoxin units.

\section{Mice and bacterial challenge}

MC-deficient $\left(\mathrm{Kit}^{\text {Wsh-/-}}\right)$ mice were kindly provided by Dr. Mécheri (Pasteur Institute, Paris, France). Kit ${ }^{W s h-/-}$ and C57BL/6 mice were bred at the animal facilities of the institute of bacteriology (University of Strasbourg, France) according to regulations of the CREMEAS. Borrelia $\left(10^{3} / 100 \mu \mathrm{l}\right)$ were intradermally injected into the dorsal thoracic area of mice. With a biopsy punch (Stiefel laboratory), $3 \mathrm{~mm}$ skin biopsies were then collected at 3, 5, 7 and 15 days after the inoculation for Borrelia quantification by quantitative PCR (qPCR). Quantification targeting the flab gene was performed as described previously [33]. Numbers of Borrelia in the skin were normalized to $10^{4}$ GAPDH DNA copies. Organs were collected at different time points post infection to check for the presence of spirochetes, either by culture in BSK-H medium and observation under dark field microscopy (heart, joint) or by PCR (ear tissue).

\section{ELISA}

To measure IL-6 secreted by MC, enzyme-linked immunosorbent assays (ELISAs) were performed on cell supernatants. Protocols were based on sandwich techniques, as described by the manufacturer ( $R \& D$ systems, Lille, France).

\section{Flow cytometry}

MCs were centrifuged at $800 \times g$ for $15 \mathrm{~min}$ at room temperature. Cells $\left(5.10^{5}\right.$ cells $\left./ \mathrm{ml}\right)$ were resuspended in PBS-EDTA $3 \mathrm{mM}$. Fc receptors were blocked with Fc blocking reagent (CD16/CD32) for 5 min. Cells were finally processed for staining with PE-labeled rat antimouse CD 117 (eBioscience, Fontenay sous Bois, France), $(1 / 300)$ and APC-labeled american hamster anti-mouse FceRI (eBioscience, 1/300) in PBS-EDTA $3 \mathrm{mM}$ before analysis with a FACScalibur (BD Biosciences, Le Pont de Claix, France) equipped with Flowjo software.

\section{Real-time quantitative RT-PCR}

Quick-RNA MiniPrep (Zymo Research, St Quentin En Yvelines, France) was used to isolate total RNA. One microgram of total RNA for cDNA synthesis by the iScript cDNA Synthesis Kit (Bio-Rad, Marnes la Coquette, France) was used; it was amplified by real-time RT-PCR in an ABI 7300 Real-Time PCR system (Applied Biosystems, Illkirch, France). The amplification cycle consisted of initial denaturation at $95{ }^{\circ} \mathrm{C}$ for $10 \mathrm{~min}$ followed by 45 cycles each at $95{ }^{\circ} \mathrm{C}$ for $10 \mathrm{~s}$ and $60{ }^{\circ} \mathrm{C}$ for $1 \mathrm{~min}$ and a final melt curve analysis: $55^{\circ} \mathrm{C}$ for $30 \mathrm{~s}$ with an increase of $0.5^{\circ} \mathrm{C} /$ cycle to $95^{\circ} \mathrm{C}$. Primers, probes and RNA analysis reagents (TaqMan Master Mix reagents kit) used for real-time RT-PCR were obtained from Applied Biosystems (Illkirch, France). We used the comparative $\Delta \Delta \mathrm{C}_{\mathrm{T}}$ method to determine the quantification of gene expression, normalized the target gene (IL6, F: 5'-TAG TCC TTC CTA CCC CAA TTT CC-3' and R: 5'-TTG GTC CTT AGC CAC TCC TTC-3'; MCP-1, F: 5'-CTT CTG GGC CTG CTG TTC-3' and R: $5^{\prime}$-CCA GCC TAC TCA TTG GGA TCA-3'; FlaB, F: 5'-TTT CAG GGT CTC AAG CGT CCT G-3' and R: 5' -GCA GGT GCT GGC TGT TGA GC-3') expression in the test samples to the endogenous reference GAPDH (F: 5' -CCA ACC GCG AGA AGA TGA CC-3' and R: 5'-GAT CTT CAT GAG GTA GTC AGT-3') level and reported them as the fold difference relative to GAPDH gene expression in untreated baseline control. We performed all the assays in triplicate and repeated the experiments at least three times.

\section{Statistical analyses}

Each experiment was carried out at least three times in independent experiments. The most representative experiment is shown. Results represent the mean \pm standard 
deviation (SD) of at least triplicates of one experiment and were analyzed by two-tailed Student's $t$-test or ANOVA with Tukey post-hoc test using GraphPad software. Differences in values were considered significant if $P<0.05$ (" $P<0.05$; ** $P<0.01$; $\left.{ }^{* * * *} P<0.001\right)$. For in vivo studies, a minimum of 5 mice has been used at each time point of the kinetics to get significant results.

\section{Results}

Borrelia burgdorferi (s.s.) 297 and its lipoprotein L-OspC differently activate mast cells

Primary MCs generated by culturing mice bone marrow cells for 4 weeks with IL-3/SCF were used. To study the impact of Borrelia on MC activation, primary MCs were incubated with different concentrations of B. burgdorferi (s.s.) 297 or its surface lipoprotein OspC (Fig. 1). Degranulation was only induced by L-OspC, not by whole B. burgdorferi (s.s.) 297 (Fig. 1a) or by unlipidated OspC protein (data not shown). However, both L-OspC and Borrelia induced proinflammatory cytokine and chemokine expression by $\mathrm{MC}$ at protein (IL-6) and mRNA (IL-6 and MCP-1) levels (Fig. 1b-d). Cathelicidin, an antimicrobial peptide well-known to be produced by MCs [22], was poorly or not induced in our experiment (data not shown).

\section{L-OspC is not essential for murine mast cell activation by Borrelia}

OspC is an essential lipoprotein for the transmission of Borrelia from the tick to the vertebrate host [27, 28].
However, to determine whether L-OspC is essential for $\mathrm{MC}$ activation in vitro in the context of the whole bacteria, we activated primary $\mathrm{MC}$ with an OspC-KO mutant strain of B. burgdorferi (s.s.) 297 (Fig. 2). We show here that IL-6 protein secretion as well as IL-6 and MCP-1 mRNA expression were similarly induced by wild type, mutant and the complemented strains.

\section{Mast cell inflammatory response against Borrelia is inhibited in part by tick saliva}

Since B. burgdorferi (s.s.) 297 transmission occurs in the presence of tick saliva, we explored its effect on the MC inflammatory response in vitro (Fig. 3). Tick salivary gland extract (SGE) was incubated with primary MCs in the presence or absence of B. burgdorferi (s.s.) 297. Tick SGE induces mast cell degranulation, but MC-degranulation induced by tick SGE is reduced in the presence of Borrelia (Fig. 3a). Moreover, tick SGE significantly inhibits the IL-6 (t-test: $t_{(4)}=7.03, P=0.002$ for mRNA, t-test: $t_{(5)}=9.74$, $P=0.0002$ for protein) and MCP-1 (t-test: $t_{(5)}=2.93$, $P=0.032)$ expression induced by Borrelia-activated MC (Fig. 3b-d).

\section{Mast cells do not impact B. burgdorferi (s.s.) 297} amplification and dissemination during primary infection We have seen that B. burgdorferi (s.s.) 297 activates primary $\mathrm{MCs}$ in vitro in an L-OspC-independent way. However, the role of $\mathrm{MC}$ in vivo during B. burgdorferi (s.s.) 297 infection has never been investigated so far. To
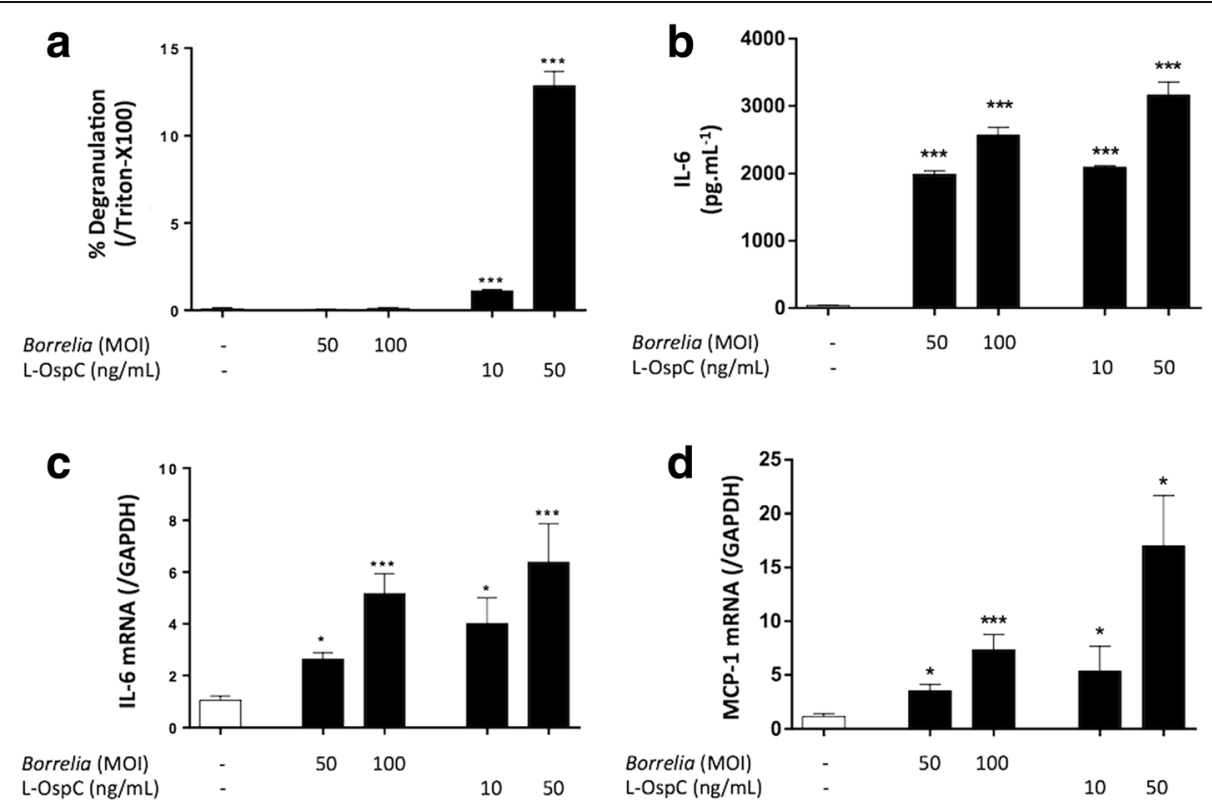

Fig. 1 Mouse mast cell response to Borrelia and OspC. Primary MCs from C57BL/6 mice were activated with different concentrations of Borrelia burgdorferi (s.s.) 297 strain (MOI 10:1 or 50:1) or Lipidated-OspC (L-OspC: 10 or 50 ng/ml). After 2 h, the level of degranulation was evaluated by measuring $\beta$ hexasominidase release and percentage degranulation was calculated according to the negative control (a). After $24 \mathrm{~h}$, supernatants were collected to measure IL-6 concentration by ELISA (b). After 6 h, RNAs were collected to measure IL- 6 and MCP-1 mRNA expression $\left(\mathbf{c}\right.$, d). ${ }^{*} P<0.05$; ${ }^{* * *} P<0.001$ 

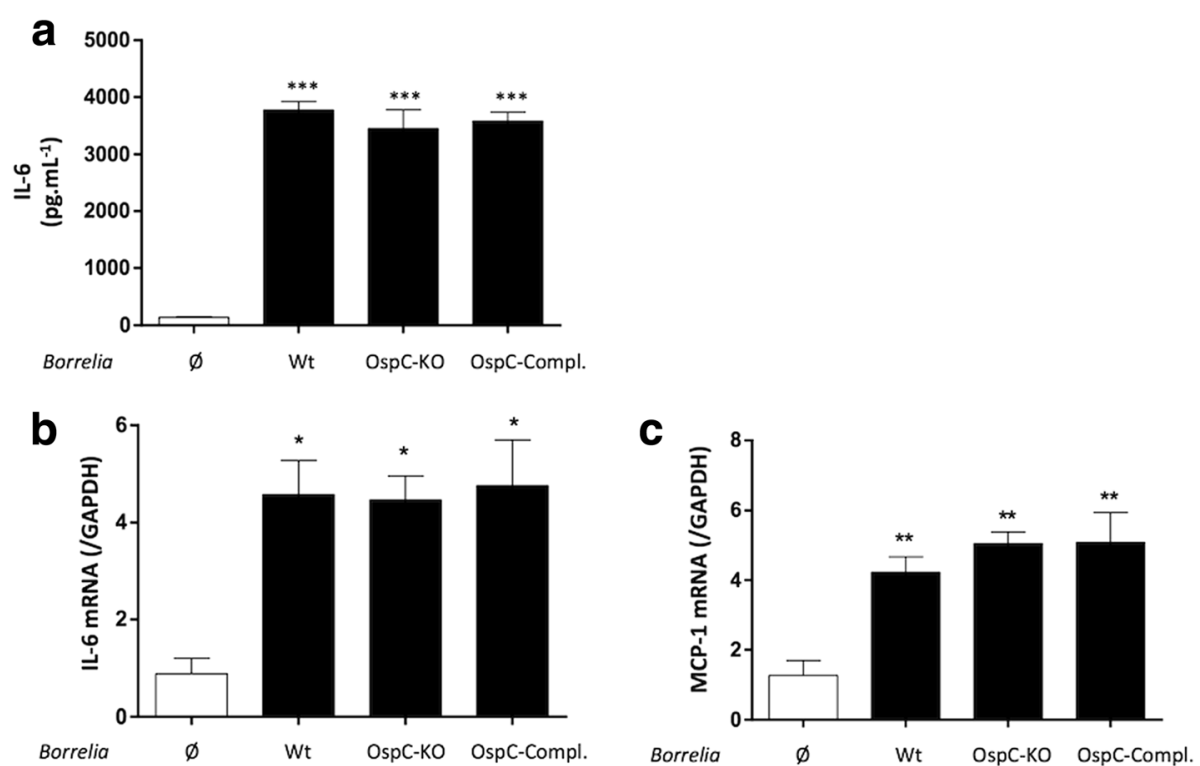

Fig. 2 Mouse mast cell response to Borrelia OspC-KO. Primary MCs from C57BL/6 mice were activated with medium (Ø) Borrelia burgdorferi (s.s.) (Bb) 297 (Wt), Bb OspC-KO (OspC-KO) or Bb OspC-complemented strains (OspC-Compl.) (MOI 50:1). After 24 h, supernatants were collected to measure IL-6 concentration by ELISA (a). After $6 \mathrm{~h}$ RNAs were collected to measure IL-6 and MCP-1 mRNA expression (b, c). ${ }^{*} P<0.05 ;{ }^{* *} P<0.01$; ${ }^{* * *} P<0.001$

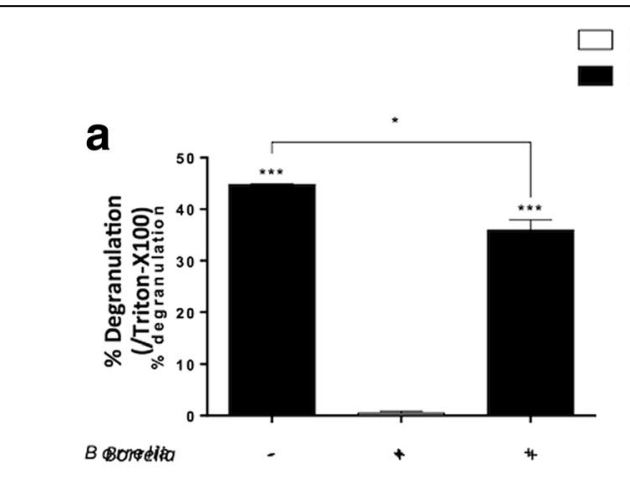

\section{No SGE \\ SGE}
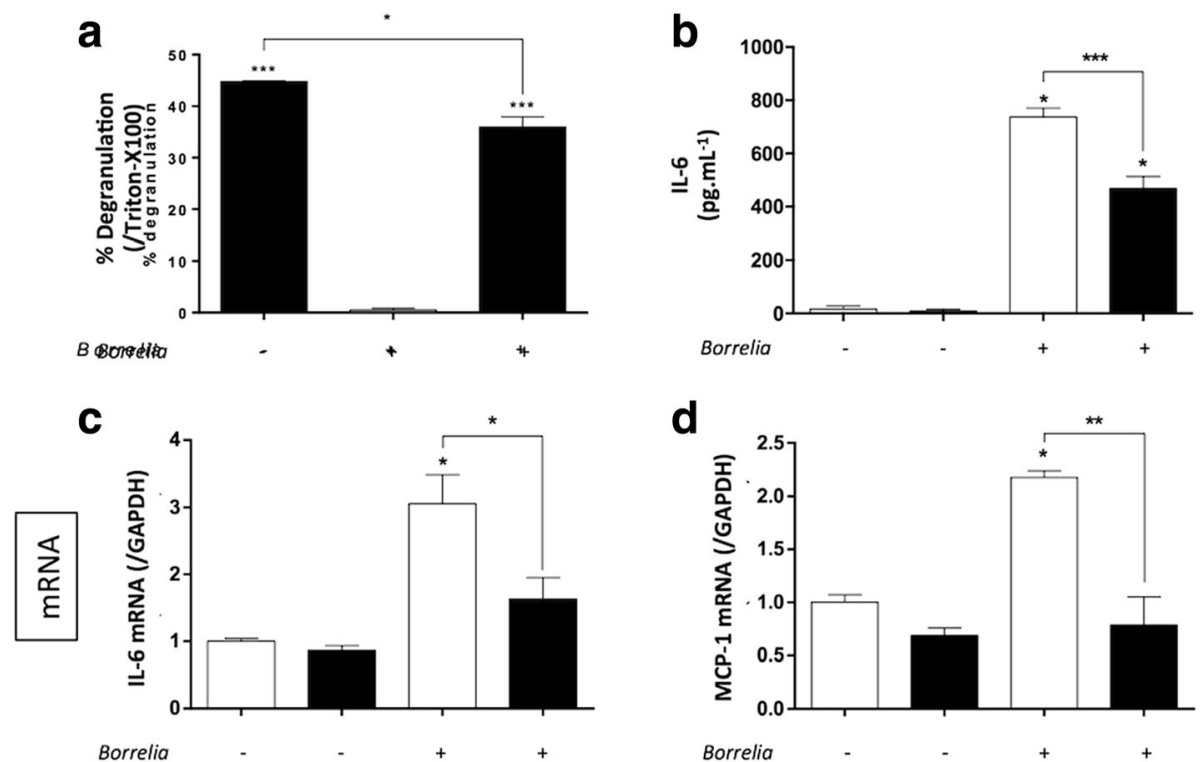

Fig. 3 Impact of tick saliva on mouse mast cell inflammatory response. Primary MCs from C57BL/6 mice were activated with Borrelia burgdorferi (s.s.) 297 strain (MOI 50:1) in the absence (white bars) or presence (black bars) of tick salivary gland extract (SGE: $20 \mu \mathrm{g} / \mathrm{ml}$ ). After $2 \mathrm{~h}$, the level of degranulation was evaluated by measuring $\beta$-hexasominidase release and percentage degranulation was calculated (a). After $24 \mathrm{~h}$, supernatants were collected to measure IL-6 concentration by ELISA (b). After 6 h, RNAs were collected to measure IL-6 and MCP-1 mRNA expression (c, d). ${ }^{*} P<0.05 ;{ }^{* *} P<0.01 ;{ }^{* *} P<0.001$ 
explore the impact of MC during mouse infection by $B$. burgdorferi (s.s.) 297, we analyzed bacteria multiplication in the skin as well as its dissemination in wild type C57BL/6 versus Kit ${ }^{\text {Wsh-/- }}$ mice (Fig. 4, Table 1). No significant difference was observed in terms of bacteria multiplication in the skin (ANOVA: $F_{(3,65)}=0.43$, $P=0.72$ ) (Fig. 4). Borrelia dissemination in mice was not significantly altered in the absence of mast cells, although one $\mathrm{Kit}^{\mathrm{Wsh-1-}}$ mouse showed a positive Borrelia count at day 15 at the ear while all C57BL/6 mice were negative (Table 1).

\section{Discussion}

The skin is one of the first defense organ that pathogens have to cross to infect the host in the context of arthropod-borne diseases [5, 34]. Some bacteria, parasites and viruses have evolved to use vectors, such as ticks and mosquitoes, to bypass this physical barrier. However, once pathogens have been injected into the skin by vectors, they have to face a biological barrier made of skin cells and inflammatory molecules. In Lyme borreliosis, bacteria remain in the skin for days, first interacting with resident skin cells and immune cells before disseminating to target organs (joints, ear, heart, nervous system). Those cells, including keratinocytes, fibroblasts, macrophages, dendritic cells, neutrophils, NK cells, $\mathrm{T}$ and $\mathrm{B}$ cells secrete inflammatory molecules such as antimicrobial peptides, cytokines, chemokines, adhesins and reactive oxygen species to stop the infection [31-42]. MCs are present in the skin in large quantity.

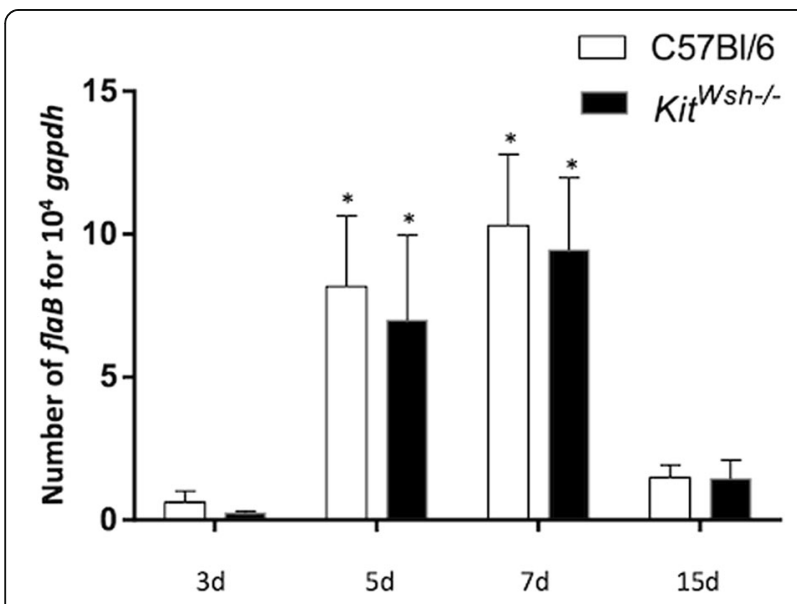

Fig. 4 Role of mast cells upon mouse infection by Borrelia. C57BL/6 (white bars) or Kit ${ }^{\text {Wh }}$-1- (black bars) mice were infected intradermally with Borrelia burgdorferi (s.s.) (Bb) 297 strain $\left(10^{3}\right.$ bacteria/100 $\mu$ l) by syringe inoculation. The relative quantification of $\mathrm{Bb}$, presented as copies of flab transcript per $10^{4}$ copies of gapdh transcripts, at the site of inoculation (skin of the mouse back) was measured by qPCR at different time points ( $d=$ day) after the infection. Results of three separate experiments are presented. ${ }^{*} P<0.05$
Table 1 Impact of mast cell deficiency on B. burgdorferi (s.s.) 297 dissemination

\begin{tabular}{|c|c|c|c|}
\hline Day/ Organ & Joints (\%) & Heart (\%) & Ear $(\%)^{a}$ \\
\hline \multicolumn{4}{|l|}{ C57BL/6 (10 weeks) } \\
\hline Day $3(n=8)$ & 0 & 0 & 0 \\
\hline Day $5(n=8)$ & 0 & 0 & 0 \\
\hline Day $7(n=5)$ & 60 & 0 & 0 \\
\hline Day $15(n=8)$ & 75 & 0 & 0 \\
\hline \multicolumn{4}{|l|}{ Kit Wsh -I- $(10$ weeks $)$} \\
\hline Day $3(n=7)$ & 0 & 0 & 0 \\
\hline Day $5(n=10)$ & 10 & 0 & 0 \\
\hline Day $7(n=12)$ & 50 & 0 & 0 \\
\hline Day $15(n=10)$ & 90 & 0 & 10 \\
\hline
\end{tabular}

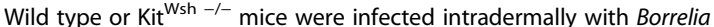
burgdorferi 297 strain $\left(10^{3}\right.$ bacteria/100 $\mu$ l) by syringe inoculation. The dissemination of Borrelia was determined by in vitro culture and by QPCR performed on the different distant organs: the joint, the heart and the ear ${ }^{a}$ The percentage of positive samples to Borrelia is calculated according to 5 mice minimum per group

Abbreviations: $n$ number of mice per group, day day of infection

Early studies on the interaction of MCs with B. burgdorferi (s.s.) have been done with rat peritoneal MCs and murine MC/9 MCs line [25, 26], and, to our knowledge, the ability of mice primary MCs to interact with Borrelia has not been investigated to date. Cell lines are widely used in many types of cancer research as well as in immunological or metabolism studies. However, their behavior may differ from primary cells [42]. We thus decided to explore the ability of mouse primary MCs to respond to B. burgdorferi (s.s.) 297. Primary MCs express IL-6 and MCP-1 in response to Borrelia. The expression of these two genes has been shown in mouse skin in response to Borrelia infection [3]. Moreover, IL-6 has been essentially associated with late symptoms such as arthritis and neuroborreliosis [43, 44], but also with erythema migrans and with late skin symptoms [45]. IL-6 is of importance since this cytokine has a crucial role during the transition from innate to acquired immunity. Its potential release in the skin by resident MCs might participate in early cell attraction such as neutrophils [46]. MCs also express IL-6 and MCP-1 in response to LOspC. OspC is an essential lipoprotein when it enters the host skin and is already expressed by the bacteria during the tick blood meal [47]. If OspC role is not clear, its involvement in the early course of the infection has been demonstrated [28] and recent data [48] tend to indicate that it has an antiphagocytic activity. Also, OspC exhibits a protective role against the innate immune system [49]. A previous study has determined the inability of the lipoprotein OspA to activate TNF- $\alpha$ secretion by MC/9 MCs [25]. OspA is mainly expressed in ticks and is downregulated during the early transmission to the 
vertebrate hosts [50]. MC activation thus differs between Borrelia lipoproteins, since the lipidated OspC protein induced a strong degranulation, but not OspA nor the unlipidated $\mathrm{OspC}$ protein. Moreover, although lipoproteins are the major molecules on the surface of the bacteria [51], whole Borrelia parasites do not induce mast cell degranulation of mast cell line [25] and primary mast cells. Altogether, we can assume that the lipid part of OspC, anchored and hidden in the bacteria membranes, induces degranulation. Moreover, the amount of OspC present on the whole bacteria might be not sufficient to induce degranulation compared to the purified lipoprotein. Globally, the differences might be due to the cell state (line versus primary) or molecules studied (TNF- $\alpha$ versus IL-6/MCP-1). However, OspC is not sufficient and the only lipoprotein involved in MC activation in the context of the whole bacteria since an OspC-deficient strain of B. burgdorferi (s.s.) 297 still activates MC similarly to the wild type. Borrelia is recognized by different Toll like receptors (TLRs) [52] and the absence of OspC might be counteracted by other Borrelia surface antigens like flagellin interacting with TLR5. It might also be balanced by the presence of other lipoproteins or even other ligands since $B$. burgdorferi (s.s.) 297 activate immune cells through many PRRs [53]. Our experiment also suggests that in contrast to lipopolysaccharides or lipotechoic acid [54], Borrelia and its lipoprotein are not able to induce cathelicidin expression by MCs. This might be due to the different TLRs those ligands are associated with.

During Borrelia transmission to the vertebrate host, bacteria are injected into the skin with tick saliva. We have shown here that tick salivary gland extract significantly but not completely inhibits IL-6 and MCP-1 expression by MCs. The ability of tick saliva to decrease inflammatory cytokine secretion was already observed on other cell types such as keratinocytes, dendritic cells and $\mathrm{T}$ cells. To determine whether the inhibition is due to a direct binding of salivary molecules to the bacteria, or to the cells, requires further studies, given the complexity of the tick saliva [11]. The impact of tick saliva on MCs during B. burgdorferi (s.s.) 297 transmission has not been investigated before. However, the involvement of MCs during non-infectious tick bite was analyzed in several studies. Histological analyses of BALB/c mice skin after Dermacentor variabilis tick bite, revealed an increased number of MCs especially after second or third tick infestation $[55,56]$. Similar observations were made with Ixodes ricinus infested rabbits [57]. However, the role of MCs in acquired tick resistance seems to depend on the tick species involved [56, 58]. Although tick saliva induces MC degranulation, it is also known to contain molecules able to counteract granules-contained mediators after their release. For instance, tick saliva contains lipocalins which can bind histamine to inhibit their functions, especially itching feelings [59]. Interestingly, we have seen that $B$. burgdorferi inhibits in part the MCs degranulation induced by tick saliva. This mechanism might help the bacteria to reduce inflammation. Similar observation was made with another bacteria, a non-pathogenic Escherichia coli strain, able to inhibit anti-2,4 dinitrophenol IgE sensitized MCs degranulation [60]. However, it remains to be explored if the B. burdorferi mediated inhibition of the degranulation induced by tick saliva is specific to this spirochete or not.

Borrelia burgdorferi (s.s.) multiplies first in the skin of $\mathrm{C} 3 \mathrm{H} / \mathrm{HeN}$ mouse before to efficiently disseminate to target organs such as the heart, the brain or the joints [33]. We thus explored the impact of MCs deficiency on the multiplication and the dissemination of the bacteria using a MC deficient murine model. This model already revealed an important role of MCs during Leishmania infection, a vector-borne disease transmitted by Phlebotomus sand flies [61, 62]. Since in Lyme borreliosis, the role of MCs has never been investigated in vivo, we infected MC deficient mice with B. burgdorferi (s.s.) 297 and compared to wild type mice, C57BL/6. Interestingly, the absence of MC does not influence bacteria multiplication happening at day $5 / 7$ post infection in mice as previously described in $\mathrm{C} 3 \mathrm{H} / \mathrm{HeN}$ mice infected with Borrelia [3]. It does not alter significantly the bacteria dissemination ability neither. Despite the MC ability of this mouse strain to promote in vitro an inflammatory response against Borrelia, in our in vivo model, mast cells do not control bacterial proliferation during primary infection and the establishment of the primary infection. It is also known that the genetic background of MCs deficient mice (C57BL/6) is not optimal to study $B$. burgdorferi (s.s.) 297 infection since it shows some resistance [63]. MCs might have a higher impact on more susceptible mice such as $\mathrm{C} 3 \mathrm{H} / \mathrm{HeN}$ mice, but no $\mathrm{MC}$ deficient mice are available in this genetic background. In addition, we had to wait 10 weeks in $\mathrm{Kit}^{\mathrm{W}}{ }^{\mathrm{Wh}}{ }^{-/-}$mice to get a very low level of MCs [64]. This age might also likely affect the outcome of infection since in $\mathrm{C} 3 \mathrm{H} / \mathrm{HeN}$ mice, the infection of mice with Borrelia is usually performed at 3 weeks of age. As with tick infestation $[55,56]$, a role of MCs could occur during secondary of tertiary infection by B. burgdorferi (s.s.) 297. Moreover, MC might have a role on long term infection, by stimulating the adaptive system [65].

\section{Conclusions}

MCs have been associated to the disease severity in malaria, another vector-borne disease [66]. In Lyme disease, these cells appear to be of lesser importance against Borrelia. In our study, we show that MCs do not have a 
protective role against Borrelia infection in vivo. However, these cells might be important for repeated infections. In patients regularly bitten by ticks, a skin inflammatory response is clearly described $[67,68]$ with an IgE antibody response against tick saliva [69]. The impact of tick saliva resistance on a subsequent Borrelia infection remains to be explored in models such as guinea pigs, since mice do not really develop tick saliva resistance [70].

\section{Additional file}

Additional file 1: Figure S1. Mast cell purity analyzed by flow cytometry. Primary MCs generated by culturing mice bone marrow cells for 4 weeks with IL-3/SCF were processed for staining with PE-labeled rat anti-mouse CD 117 and APC-labeled american hamster anti-mouse FcERI. A FACScalibur equipped with Flowjo software was used for flow cytometry analysis. (TIFF $8219 \mathrm{~kb}$ )

\section{Abbreviations}

ELISA: Enzyme-linked immunsorbent assay; IL: Interleukin; MC: Mast cell; NEAA: Non-essential amino acid; Ol: Multiplicity of infection; Osps: Outer surface proteins; Pamp: Pathogen-associated molecular pattern; PRR: Pattern recognition receptor; $\mathrm{QPCR}$ : Quantitative polymerase chain reaction; SCF: Stem cell factor; SGE: Salivary gland extract; TLR: Toll-like receptor

\section{Acknowledgements}

We thank B. Jaulhac and L. Zilliox from the French National Reference Centre of Borrelia for the culture of Borrelia strains and Dr. J. Hovius (University Amsterdam, Holland) for providing OspC-KO B. burgdorferi (s.s.) 297, Dr. B. Luft (University of Stonybrook, NY, USA) for providing OspC lipoprotein, Prof L. Gern and Dr. M. Voordouw (University of Neuchâtel, Suisse) for their help in maintaining the tick colony. We also thank C. Barthel and E. Collin for their technical support for PCR and culture of mouse organs.

\section{Funding}

QB was supported for his PhD by the Direction Générale de l'Armement and the Conseil Régional d'Alsace. NB was supported by a Fulbright grant during her sabbatical in Professor Gallo's laboratory at UCSD, California. AdiN was supported by a grant NIH 1R01Al093957-01.

\section{Availability of data and materials}

All data generated or analyzed during this study are included in this published article and its supplementary information files.

\section{Authors' contributions}

$\mathrm{QB}, \mathrm{ZW}$ and NB performed the research; $\mathrm{QB}, \mathrm{ADN}, \mathrm{NB}$ and ZW designed the research study; $A D N$ contributed essential reagents or tools; $Q B, N B, A D N$ and ZW analyzed the data; QB, A DN and NB wrote the paper. All authors read and approved the final manuscript.

\section{Competing interests}

The authors declare that they have no competing interests.

\section{Consent for publication}

Not applicable.

\section{Ethics approval and consent to participate}

The experiments reported herein were approved by the Ethics Committee of the University of Strasbourg under the \# 00642.01.

\section{Publisher's note}

Springer Nature remains neutral with regard to jurisdictional claims in published maps and institutional affiliations.

\section{Author details}

'EA7290 Virulence bactérienne précoce: groupe borréliose de Lyme, Fédération de médecine translationnelle et Faculté de Pharmacie de Strasbourg, Université de Strasbourg, Strasbourg, France. ${ }^{2}$ Department of Dermatology, University of California, San Diego, USA. ${ }^{3}$ Centre National de Reference Borrelia, Centre Hospitalier Universitaire, Strasbourg, France.

${ }^{4}$ Present address: Department of Veterinary Medicine, University of Maryland, College Park, USA

Received: 17 October 2016 Accepted: 12 June 2017

Published online: 27 June 2017

\section{References}

1. Tijsse-Klasen E, Koopmans MPG, Sprong H. Tick-borne pathogen - reversed and conventional discovery of disease. Fron Public Heal. 2014;2:73.

2. Burgdorfer W, Barbour AG, Hayes SF, Benach JL, Grunwaldt E, Davis JP. Lyme disease - a tick-borne spirochetosis? Science. 1982;216:1317-9.

3. Kern A, Schnell G, Bernard Q, Bøuf A, Jaulhac B, Collin E, et al. Heterogeneity of Borrelia burgdorferi sensu stricto population and its involvement in Borrelia pathogenicity: study on murine model with specific emphasis on the skin interface. PLoS One. 2015;10:7.

4. Shih CM, Pollack RJ, Telford SR, Spielman A. Delayed dissemination of Lyme disease spirochetes from the site of deposition in the skin of mice. J Infect Dis. 1992;166:827-31.

5. Bernard Q, Jaulhac B, Boulanger N. Smuggling across the border: how arthropod-borne pathogens evade and exploit the host defense system of the skin. J Invest Dermatol. 2014;134:1211-9.

6. Skallová A, lezzi G, Ampenberger F, Kopf M, Kopecky J. Tick saliva inhibits dendritic cell migration, maturation, and function while promoting development of Th2 responses. J Immunol. 2008;180:6186-92.

7. Marchal C, Schramm F, Kern A, Luft BJ, Yang X, Schuijt TJ, et al. Antialarmin effect of tick saliva during the transmission of Lyme disease. Infect Immun. 2011:79:774-85.

8. Severinová J, Salát J, Krocová Z, Reznícková J, Demová H, Horká H, et al. Coinoculation of Borrelia afzelii with tick salivary gland extract influences distribution of immunocompetent cells in the skin and lymph nodes of mice. Folia Microbiol. 2005:50:457-63.

9. Kotsyfakis M, Sá-Nunes A, Francischetti IMB, Mather TN, Andersen JF, Ribeiro JMC. Antiinflammatory and immunosuppressive activity of sialostatin L, a salivany cystatin from the tick Ixodes scapularis. J Biol Chem. 2006;281:26298-307.

10. Mejri N, Rutti B, Brossard M. Immunosuppressive effects of Ixodes ricinus tick saliva or salivary gland extracts on innate and acquired immune response of BALB/c mice. Parasitol Res. 2002;88:192-7.

11. Kazimírová M, Štibrániová I. Tick salivary compounds: their role in modulation of host defences and pathogen transmission. Front Cell Infect Microbiol. 2013;3:43.

12. Marchal CMP, Luft BJ, Yang X, Sibilia J, Jaulhac B, Boulanger N. Defensin is suppressed by tick salivary gland extract during the in vitro interaction of resident skin cells with Borrelia burgdorferi. J Invest Dermatol. 2009;129: 2515-7

13. Schuijt TJ, Hovius JWR, van Burgel ND, Ramamoorthi N, Fikrig E, van Dam AP. The tick salivary protein Salp15 inhibits the killing of serum-sensitive Borrelia burgdorferi sensu lato isolates. Infect Immun. 2008;76:2888-94.

14. Pal U, Yang $X$, Chen M, Bockenstedt LK, Anderson JF, Flavell RA, et al. OspC facilitates Borrelia burgdorferi invasion of Ixodes scapularis salivary glands. J Clin Invest. 2004;113:220-30.

15. Hovius JWR, de Jong MA, den Dunnen J, Litjens M, Fikrig E, van der Poll T, et al. Salp15 binding to DC-SIGN inhibits cytokine expression by impairing both nucleosome remodeling and mRNA stabilization. PLoS Pathog. 2008:4:2.

16. Anguita J, Ramamoorthi N, Hovius JWR, Das S, Thomas V, Persinski R, et al. Salp15, an Ixodes scapularis salivary protein, inhibits CD4(+) T cell activation. Immunity. 2002;16:849-59.

17. Hovius JWR, Levi M, Fikrig E. Salivating for knowledge: potential pharmacological agents in tick saliva. PLoS Med. 2008;5:2.

18. Galli SJ, Borregaard N, Wynn TA. Phenotypic and functional plasticity of cells of innate immunity: macrophages, mast cells and neutrophils. Nat Immunol. 2011;12:1035-44.

19. Trinchieri $\mathrm{G}$, Sher A. Cooperation of Toll-like receptor signals in innate immune defence. Nat Rev Immunol. 2007;7:179-90. 
20. Supajatura V, Ushio H, Nakao A, Akira S, Okumura K, Ra C, et al. Differential responses of mast cell Toll-like receptors 2 and 4 in allergy and innate immunity. J Clin Invest. 2002;109:1351-9.

21. Abraham SN, St John AL. Mast cell-orchestrated immunity to pathogens. Nat Rev Immunol. 2010;10:440-52.

22. Di Nardo A, Yamasaki K, Dorschner RA, Lai Y, Gallo RL. Mast cell cathelicidin antimicrobial peptide prevents invasive group a Streptococcus infection of the skin. J Immunol. 2008;180:7565-73.

23. Urb M, Sheppard DC. The role of mast cells in the defence against pathogens. PLoS Pathog. 2012;8:4.

24. Reber $L L$, Frossard N. Targeting mast cells in inflammatory diseases. Pharmacol Ther. 2014;142:416-35.

25. Talkington J, Nickell SP. Borrelia burgdorferi spirochetes induce mast cell activation and cytokine release. Infect Immun. 1999;67:1107-15.

26. Talkington J, Nickell SP. Role of Fc gamma receptors in triggering host cell activation and cytokine release by Borrelia burgdorferi. Infect Immun. 2001;69:413-9.

27. Tilly K, Bestor A, Jewett MW, Rosa P. Rapid clearance of Lyme disease spirochetes lacking OspC from skin. Infect Immun. 2007;75:1517-9.

28. Tilly K, Krum JG, Bestor A, Jewett MW, Grimm D, Bueschel D, et al. Borrelia burgdorferi OspC protein required exclusively in a crucial early stage of mammalian infection. Infect Immun. 2006;74:3554-64.

29. Wang Z, Lai Y, Bernard JJ, Macleod DT, Cogen AL, Moss B, et al. Skin mast cells protect mice against vaccinia virus by triggering mast cell receptor S1PR2 and releasing antimicrobial peptides. J Immunol. 2012;188:345-57.

30. Schwartz LB, Austen KF, Wasserman SI. Immunologic release of betahexosaminidase and beta-glucuronidase from purified rat serosal mast cells. J Immunol. 1979;123:1445-50.

31. Suzuki K, Verma IM. Phosphorylation of SNAP-23 by IkappaB kinase 2 regulates mast cell degranulation. Cell. 2008;134:485-95.

32. Schick B, Austen KF. Modulation of chymase-mediated rat serosal mast cells degranulation by trypsin or diisopropyl fluorophosphate. Immunology. 1989:66:434-8.

33. Kern A, Collin E, Barthel C, Michel C, Jaulhac B, Boulanger N. Tick saliva represses innate immunity and cutaneous inflammation in a murine model of Lyme disease. Vector Borne Zoonotic Dis. 2011;11:1343-50.

34. Bernard Q, Jaulhac B, Boulanger N. Skin and arthropods: an effective interaction used by pathogens in vector-borne diseases. Eur J Dermatol. 2015;25(Suppl 1):18-22.

35. Schramm F, Kern A, Barthel C, Nadaud S, Meyer N, Jaulhac B, et al. Microarray analyses of inflammation response of human dermal fibroblasts to different strains of Borrelia burgdorferi sensu stricto. PLoS One. 2012;7:6.

36. Strle K, Drouin EE, Shen S, El Khoury J, McHugh G, Ruzic-Sabljic E, et al. Borrelia burgdorferi stimulates macrophages to secrete higher levels of cytokines and chemokines than Borrelia afzelii or Borrelia garinii. J Infect Dis. 2009:200:1936-43.

37. Filgueira L, Nestle F, Rittig M, Joller H, Groscurth P. Human dendritic cells phagocytose and process Borrelia burgdorferi. J Immunol. 1996;157:2998-3005.

38. Ebnet K, Brown KD, Siebenlist UK, Simon MM, Shaw S. Borrelia burgdorferi activates nuclear factor-kappa B and is a potent inducer of chemokine and adhesion molecule gene expression in endothelial cells and fibroblasts. J Immunol. 1997;158:3285-92.

39. Hannier S, Liversidge J, Sternberg JM, Bowman AS. Characterization of the B-cell inhibitory protein factor in Ixodes ricinus tick saliva: a potential role in enhanced Borrelia burgdoferi transmission. Immunology. 2004;113:401-8.

40. Wang J, Li Y, Kinjo Y, Mac T-T, Gibson D, Painter GF, et al. Lipid binding orientation within CD1d affects recognition of Borrelia burgorferi antigens by NKT cells. Proc Natl Acad Sci USA. 2010;107:1535-40.

41. Vesely DL, Fish D, Shlomchik MJ, Kaplan DH, Bockenstedt LK. Langerhans cell deficiency impairs Ixodes scapularis suppression of Th1 responses in mice. Infect Immun. 2009;77:1881-7.

42. Pan C, Kumar C, Bohl S, Klingmueller U, Mann M. Comparative proteomic phenotyping of cell lines and primary cells to assess preservation of cell type-specific functions. Mol Cell Proteomics. 2008;8:443-50.

43. Anguita J, Rincón M, Samanta S, Barthold SW, Flavell RA, Fikrig E. Borrelia burgdorferi-infected, interleukin-6-deficient mice have decreased Th2 responses and increased Lyme arthritis. J Infect Dis. 1998;178:1512-5.

44. Pachner AR, Amemiya K, Delaney E, O'Neill T, Hughes CA, Zhang WF. Interleukin-6 is expressed at high levels in the CNS in Lyme neuroborreliosis. Neurology. 1997:49:147-52.

45. Müllegger RR, McHugh G, Ruthazer R, Binder B, Kerl H, Steere AC. Differential expression of cytokine mRNA in skin specimens from patients with erythema migrans or acrodermatitis chronica atrophicans. J Invest Dermatol. 2000;115:1115-23.

46. Scheller J, Chalaris A, Schmidt-Arras D, Rose-John S. The pro- and antiinflammatory properties of the cytokine interleukin-6. Biochim Biophys Acta. 1813;2011:878-88

47. Schwan TG, Piesman J. Temporal changes in outer surface proteins a and $\mathrm{C}$ of the lyme disease-associated spirochete, Borrelia burgdorferi, during the chain of infection in ticks and mice. J Clin Microbiol. 2000;38:382-8.

48. Carrasco SE, Troxell B, Yang Y, Brandt SL, Li H, Sandusky GE, et al. Outer surface protein OspC is an antiphagocytic factor that protects Borrelia burgdorferi from phagocytosis by macrophages. Infect Immun. 2015:83:4848-60.

49. Seemanapalli SV, Xu Q, McShan K, Liang FT. Outer surface protein C is a dissemination-facilitating factor of Borrelia burgdorferi during mammalian infection. PLoS One. 2010;5:12.

50. Ohnishi J, Piesman J, de Silva AM. Antigenic and genetic heterogeneity of Borrelia burgdorferi populations transmitted by ticks. Proc Natl Acad Sci USA. 2001:98:670-5.

51. Xu Q, McShan K, Liang FT. Essential protective role attributed to the surface lipoproteins of Borrelia burgdorferi against innate defences. Mol Microbiol. 2008;69:15-29.

52. Cervantes JL, Hawley KL, Benjamin SJ, Weinerman B, Luu SM, Salazar JC. Phagosomal TLR signaling upon Borrelia burgdorferi infection. Front Cell Infect Microbiol. 2014;4:55.

53. Oosting $M$, Buffen $K$, van der Meer JWM, Netea MG, Joosten LAB. Innate immunity networks during infection with Borrelia burgdorferi. Crit Rev Microbiol. 2014;42:1-12.

54. Di Nardo A, Vitiello A, Gallo RL. Cutting edge: mast cell antimicrobial activity is mediated by expression of cathelicidin antimicrobial peptide. J Immunol. 2003;170:2274-8.

55. denHollander N, Allen JR. Dermacentor variabilis: acquired resistance to ticks in BALB/c mice. Exp Parasitol. 1985;59:118-29.

56. Steeves EB, Allen JR. Tick resistance in mast cell-deficient mice: histological studies. Int J Parasitol. 1991;21:265-8.

57. Brossard M, Fivaz V. Ixodes ricinus L.: mast cells, basophils and eosinophils in the sequence of cellular events in the skin of infested or re-infested rabbits. Parasitology. 1982;85:583-92.

58. Matsuda H, Fukui K, Kiso Y, Kitamura $Y$. Inability of genetically mast celldeficient W/Wv mice to acquire resistance against larval Haemaphysalis longicornis ticks. J Parasitol. 1985;71:443-8.

59. Mans BJ. Tick histamine-binding proteins and related lipocalins: potential as therapeutic agents. Curr Opin Investig Drugs. 2005;6:1131-5.

60. Magerl M, Lammel V, Siebenhaar F, Zuberbier T, Metz M, Maurer M. Nonpathogenic commensal Escherichia coli bacteria can inhibit degranulation of mast cells. Exp Dermatol. 2008;17:427-35.

61. Maurer M, Lopez Kostka S, Siebenhaar F, Moelle K, Metz M, Knop J, et al. Skin mast cells control T cell-dependent host defense in Leishmania major infections. FASEB J. 2006;20:2460-7.

62. Dudeck A, Suender CA, Kostka SL, von Stebut E, Maurer M. Mast cells promote Th1 and Th17 responses by modulating dendritic cell maturation and function. Eur JImmunol. 2011:41:1883-93.

63. Ma Y, Seiler KP, Eichwald EJ, Weis JH, Teuscher C, Weis JJ. Distinct characteristics of resistance to Borrelia burgdorferi-induced arthritis in C57BL/ 6N mice. Infect Immun. 1998;66:161-8.

64. Grimbaldeston MA, Chen CC, Piliponsky AM, Tsai M, Tam SY, Galli SJ. Mast cell-deficient $W$-sash c-kit mutant Kit ${ }^{W-s h W \text {-sh }}$ mice as a model for investigating mast cell biology in vivo. Am J Pathol. 2005;167:835-48.

65. Galli SJ, Nakae S, Tsai M. Mast cells in the development of adaptive immune responses. Nat Immunol. 2005;6:135-42.

66. Wilainam P, Nintasen R, Viriyavejakul P. Mast cell activation in the skin of Plasmodium falciparum malaria patients. Malar J. 2015;14:67.

67. Elston DM. Tick bites and skin rashes. Curr Opin Infect Dis. 2010;23:132-8.

68. Krause PJ, Grant-Kels JM, Tahan SR, Dardick KR, Alarcon-Chaidez F, Bouchard $K$, et al. Dermatologic changes induced by repeated Ixodes scapularis bites and implications for prevention of tick-borne infection. Vector-Borne Zoonotic Dis. 2009;9:603-10.

69. Burke G, Wikel SK, Spielman A, Telford SR, McKay K, Krause PJ. Hypersensitivity to ticks and Lyme disease risk. Emerg Infect Dis. 2005;11:36-41.

70. Wada T, Ishiwata K, Koseki H, Ishikura T, Ugajin T, Ohnuma N, et al. Selective ablation of basophils in mice reveals their nonredundant role in acquired immunity against ticks. J Clin Invest. 2010;120:2867-75. 